\title{
CDISC SDTM Vital Sign Test Name Terminology
}

National Cancer Institute

\section{Source}

National Cancer Institute. CDISC SDTM Vital Sign Test Name Terminology. NCI

Thesaurus. Code C67153.

Terminology codelist used with Vital Sign Test Name within the Clinical Data Interchange Standards Consortium Study Data Tabulation Model. 